\title{
Design of Network Teaching System Based on Autonomous Learning and Cooperative Learning
}

\author{
Wei Zhang ${ }^{1, a^{*}}, H_{e} \operatorname{Pan}^{1, b}$, Taihao $\mathrm{Li}^{1, \mathrm{c}}$, Ruiqing Qie $\mathrm{ed}^{2,}$ \\ ${ }^{1}$ Information technology teaching and management center, Jilin Agricultural University, Changchun \\ 130118, China \\ ${ }^{2}$ College of Economics and Management, Jilin Agricultural University, Changchun, 130000, China \\ a24683708@qq.com, ${ }^{b}$ panhe@jlau.edu.cn, cthlee@jlau.edu.cn, ${ }^{\text {c }}$ qieruiqing@126.com
}

Keywords: autonomous learning; cooperative learning; network teaching system

\begin{abstract}
At present, there are problems in the mainstream network education system in domestic. It is important to carry out autonomous learning and collaborative learning support to solve that. In combination with the relevant education theory, the teaching mode under network environment can be transplanted into the network environment, and a network teaching system which can fully play the teaching mode is developed.
\end{abstract}

\section{Introduction}

With the rapid development of computer technology, multimedia technology and network technology, a new teaching form appears in the network education to bearing many forms of media elements by educational circles of deep concern and network technology. Network education not only breaks through the time and space constraints, so that learners can receive education at different times in different places, but also can achieve educational resources sharing in the whole world.

Although network education in recent years have attached great importance to the education sector has been a great development, however, compared with the traditional education, its history is quite short, in the process of the development of network education still exist some in-depth study and continue to explore the problems remain to be. Both from technology into the field of education and the education idea change and update, or some theories guiding the network education practice and research, and support of network education technology development, there are still some has caused widespread concern, being in dispute, the problem.

Through the research of the related theory of autonomous learning and collaborative learning, summed up the relationship between autonomous learning and collaborative learning related concepts, characteristics, theoretical basis as well as two, so as to provide a strong theoretical basis for the development of the system.

The combination of autonomous learning and collaborative learning network teaching system is obtained through the developed program, the system is capable of performance is a multidiscipline teaching content, not only can support the students' Independent Learning under the network environment, and can support the learning approach based on collaboration group discussions under the network environment, and other network teaching system was developed by integrating provided which can be used for reference in the design ideas and implementation 
methods.

\section{Overall objective of system design}

The overall goal of the system design is the use of ASP technology and SQL Server 2000 database and build a suitable for multi course teaching of information system, the network teaching system should have the following characteristics:

the information teaching system applied in the course of the performance, through this system, teachers of all subjects had no need to master advanced programming skills can facilitate the development of network course.

for students in the network environment to carry out autonomous learning, collaborative learning to provide effective support environment, to support a topic based on a group discussion. Through this system, and strive to make every student in the autonomous learning, independent construction significance based on, through and member of the group, other learners, teacher exchanges and dialogue, discussion and consultation, to further improve and deepen the construction of the current study the significance of the theme.

Users of this system can be divided into three categories: teachers, students, administrators.

Teachers are designers and administrators of one or several courses. The role of teachers to management for approval after the implementation of "diao. In this system, teachers do not need to consider the realization technology of network course, is added to the system design of teaching contents and video teaching video, so you can focus on the course content, the teaching process itself. In addition to the basic knowledge of computer and network use, but also the use of office software, to understand the basic knowledge of the page. The role of students also need after management approval Diao to achieve, students should master the windows operating system, all kinds of operation, and will use Internet browser. Manager is mainly responsible for the management and maintenance of all kinds of information system, including add, delete, modify, view, etc. the operation of the students basic information, teachers' basic information, School of information, curriculum information, and administrator information.

\section{The overall design structure of the system}

The overall design structure of the system refers to the structure of the whole system, as well as the physical and logical relations between the various parts of the system. The main task of the overall structure of the design is to turn the whole system divided into several functional modules, correctly handle the internal modules and their transfer and data link, the definition of each module of the internal structure and so on. The system is composed of seven parts, which are basic information management module, course module, collaborative learning module, operation module, learning reflection module, question answering module and evaluation module. The basic information management module is mainly used for the management and maintenance of all kinds of basic information in the system, which is the premise and guarantee of the normal operation of the system.

The main function of the operation module is to arrange the homework, submit the homework and correct the homework. Teachers in this module can be taught to add homework assignments, and students to submit the work to correct. Students can view the assignment of the teacher, the job will be uploaded to the teacher. 
Learning reflection module is mainly used for the students in the process of learning in a timely manner to record some of the notes and their own learning experience in the learning process. Students can set their own learning notes as private or public form, private learning notes only to their own view, and public learning notes can be shared with teachers and other students.

Question answering module is used for non - real - time communication between students and teachers. Students can learn in their own problems encountered in the course of the teacher to leave Taiwan, etc., and other teachers on the line to answer.

The evaluation module is mainly about the evaluation of the discussion results from the study group.

Group discussion of the show as a good work for all students to learn.

From the point of view of student learning, the system can be divided into two parts, the network based autonomous learning system model and the cooperative learning system model. Network based autonomous learning is a student centered, so in the design of the full consideration of the needs of students and habits, to provide a personalized learning environment for students. In this system, a network based autonomous learning system model is shown in figure1. Mainly from the course study, submit homework, learning reflectionfi

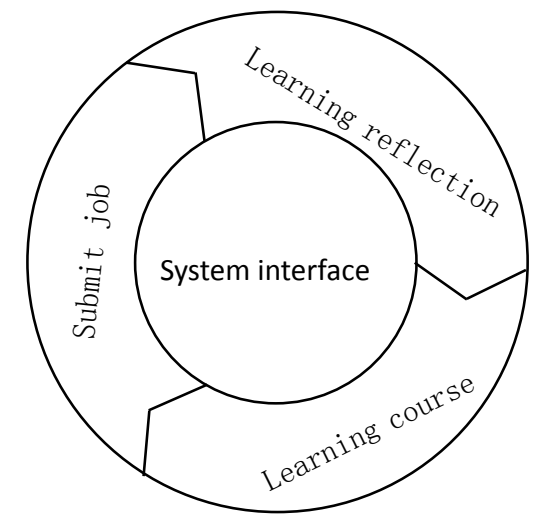

Fig. 1 model of autonomous learning system

Three parts. Students through the student subsystem interface, you can browse the contents of the course, online watch video, submit work, record a record of learning, online submission. The model of web-based collaborative learning system is mainly composed of two parts, which are cooperative learning and question answering module, as shown in Figure 2. Collaborative learning is a kind of real time communication module, which is based on the selection of the topic and the group as a unit. The question and answer module provides a kind of non real time question answering and communication mode between teachers and students. 
Fig. 2 collaborative learning system model

\section{Summary}

In this study, the analysis of the various problems existing in the present network teaching, on the basis of in-depth study of the autonomous learning and collaborative learning theory is designed into the a support autonomous learning and cooperative learning style teaching system, and to make use of ASP technology and SQL Server 2000 database, the basic realization of the system contains the basic functions.

\section{Acknowledgments}

Financial support are acknowledged from Science and Technology Development Foundation of Jilin Province grant No. 20150418079FG and National Nature Science Foundation of China, grant No. 41071160 and Philosophy and Social Sciences planning project of Changchun, grant No. CSK2014ZYJ-0018

\section{References}

[1] S. Gu: Journal of Changchun University of Science and Technology for the network teaching system of knowledge management. Vol 1(2001)

[2] Y.F. Qi: Journal of Zhengzhou Railway Vocational and Technical College. Vol 04(2010)

[3] H.Y.Zhang: China Adult Education. Vol 07 (2006) 